National Heart and Lung Institute, Imperial College London

2 University of Manchester

3 Queen Mary University, London

Correspondence to NS Hopkinson n.hopkinson@ic.ac.uk, J Vestbo Jorgen.Vestbo@manchester.ac.uk

Cite this as: BMJ2022;376:n2912 http://dx.doi.org/10.1136/bmj.n2912 Published: 12 January 2022

\title{
Should e-cigarettes be licensed as medicines?
}

\section{As the UK announces support for medicinal licensing of e-cigarettes, Nicholas S Hopkinson argues that this will give doctors another means to help smokers quit. But Jørgen Vestbo, Andrew Bush, and Jonathan Grigg say that its benefit is unproved and that harms are likely}

\author{
Nicholas S Hopkinson, ${ }^{1}$ Jørgen Vestbo, ${ }^{2}$ Andrew Bush, ${ }^{1}$ Jonathan Grigg ${ }^{3}$
}

\section{Yes-Nicholas S Hopkinson}

A recent announcement by the UK's Medicines and Healthcare Products Regulatory Agency (MHRA), ${ }^{1}$ that it "seeks to encourage the licensing of electronic cigarettes and other inhaled nicotine-containing products as drugs and aims to support companies to submit marketing authorisation applications for these products," should be welcomed.

E-cigarettes are electronic nicotine delivery systems: users inhale vapour created by heating liquid containing a humectant (propylene glycol or vegetable glycerine), nicotine, and flavourings. ${ }^{2}$ Although no serious commentator describes e-cigarettes as "completely safe," the most toxic component of tobacco smoke-solid tar particulates-as well as carbon monoxide are completely absent from e-cigarette vapour. Users' exposure levels to other constituents are orders of magnitude lower than in people who smoke. ${ }^{23}$ For this reason, the UK government's independent Committee on Toxicity of Chemicals in Food, Consumer Products and the Environment (COT) describes the relative risk of adverse health effects from vaping to be "substantially lower" than those from smoking. 4

\section{"Substantially lower" risk}

E-cigarettes are already widely available and are regulated as consumer products in accordance with the EU Tobacco Products Directive, which has been incorporated into UK law. Around 3.9 million people in the UK use e-cigarettes, two thirds of whom are now ex-smokers. ${ }^{5}$ Vaping by people who have never smoked remains rare, and in children and young people it is almost exclusively carried out among those who have been smokers or still are. ${ }^{6}$

Nevertheless, survey data show that nearly a third of smokers have never tried e-cigarettes, and around a third of smokers incorrectly believe them to be at least as harmful as conventional smoking. 5

At present, consumer regulated devices cannot be promoted as smoking cessation aids. By contrast, e-cigarettes that have been through the MHRA process and are regulated as drugs would be eligible for this therapeutic claim, in common with other licensed forms of nicotine replacement therapy. Medically licensed devices have the potential to be more effective than consumer devices because they can be made available in strengths greater than those permitted for consumer products (that is, containing more than $20 \mathrm{mg} / \mathrm{mL}$ nicotine). ${ }^{1} \mathrm{~A}$ Cochrane Collaboration systematic review already supports existing e-cigarettes as a smoking cessation aid, ${ }^{7}$ as does recently updated guidance from the National Institute for Health and Care Excellence. ${ }^{8}$

Nicotine replacement therapy is substantially more effective in the context of behavioural support, which should also be the case when the nicotine replacement comes as an e-cigarette. The MHRA process should provide further reassurance to healthcare professionals that they can help their patients to quit smoking in this way, particularly in mental health settings where smoking rates remain high.

The introduction of e-cigarettes that have been through a stricter medicinal licensing process is likely to improve confidence among smokers who so far have been reluctant to try this approach, as well as reversing false beliefs about relative harm when compared with smoking-beliefs that have been stoked by inaccurate and irresponsible reporting.

\section{One of many tools}

It is important to emphasise that medically licensed e-cigarettes, as and when they become available, will be only one among many tools to support smoking cessation, including varenicline, bupropion, and combination nicotine replacement therapy, all ideally delivered in the context of psychological support for behaviour change. Their use in this context would also be likely to increase the rate of switching completely from smoking to vaping, as opposed to dual use, and it may also help users to set a goal of limiting long term vaping. People who vape are also advised to quit it eventually-but not at the risk of going back to smoking.

It is also important to ensure that debate around e-cigarettes does not distract from other necessary tasks to achieve the UK's ambition to be smoke free by 2030 , such as introducing a "polluter pays" levy on tobacco industry profits and raising the age of sale from 18 to $21 .{ }^{9}$ To be sustainable, healthcare and other systems must reduce preventable future harm. ${ }^{10}{ }^{11}$ There are still more than six million people who smoke in the UK: medicinal licensing of e-cigarettes could help many of them to live longer, healthier lives. ${ }^{237}$

\section{No-Jørgen Vestbo, Andrew Bush, and Jonathan Grigg}

There is already enough nicotine addiction. For decades, smoking rates in the UK have been declining, and few teenagers see themselves becoming smokers. This has been achieved without e-cigarettes, and the decline in smoking has not accelerated after the introduction of e-cigarettes. ${ }^{12}$ 
If tomorrow all smokers quit and switched to e-cigarettes, we agree that fewer people would likely have respiratory disease. However, continued smoking is not a proper comparator to vaping. We have an arsenal of evidence based tools, such as further increases in taxation and decreased availability, that can further reduce smoking prevalence with far less risk of known-and unknown-adverse health effects. ${ }^{13}$

\section{No professional endorsement}

No country in the world other than the UK has licensed e-cigarettes as drugs, and for good reasons. E-cigarettes as an aid to smoking cessation have not been endorsed by a single major respiratory or paediatric scientific society because their effectiveness in smoking cessation is unproved-and remarkably poorly studied. ${ }^{14}$

In the most cited trial comparing e-cigarettes with medicinal nicotine products, e-cigarettes were found to be superior, showing a one year abstinence rate of $18 \%$, compared with $10 \% .{ }^{15}$ However, twice as many people in the "old fashioned" nicotine replacement groups were found to have quit nicotine completely, as people using e-cigarettes tend to continue vaping, whereas most people using medicinal nicotine products quit.

There is also the phenomenon of "dual use": smokers quit by using e-cigarettes and then restart smoking while they continue vaping. ${ }^{16}$ In the most cited trial, ${ }^{15} 40 \%$ of people assigned to e-cigarettes were still using them after a year, and more than half of these vapers were also smokers. (The University of Bath's Tobacco Tactics group has noted that the tobacco industry loves dual use. ${ }^{17}$ )

E-cigarettes are not " $95 \%$ less harmful than cigarettes.” This often quoted statement is indefensible because vaping has been associated with many cases of acute lung damage, events not seen in smokers. ${ }^{18}$ Around $80 \%$ of these cases are related to cutting the liquids with cannabinoids-but $20 \%$ are not. If the acute effects of vaping are worse than those of tobacco, how can anyone seriously state that the unknown long term effects are less harmful and expect to be believed?

E-cigarettes are potent triggers of airway inflammation, ${ }^{19}$ which leads to adverse respiratory effects. They contain toxicities that overlap with those of tobacco, in addition to unique toxicities. We currently cannot quantify the associated harm and translate these effects into future numbers of sick patients, but this does not justify imposing harm.

In addition, widespread use of e-cigarettes carries a substantial societal risk of accepting addiction. This acceptance will undoubtedly be increased by licensing e-cigarettes for medicinal use. E-cigarettes, as well as other heated nicotine delivery products, are marketed using the same dark arts that were used for cigarettes. ${ }^{20}$ Once adolescents are vaping, they have a six times higher risk of becoming smokers. ${ }^{21}$ Many e-cigarettes are produced and marketed by companies owned by the tobacco industry-an industry with a history of lying to the public and spending fortunes on marketing, including to teenagers. We should protect children and adolescents from these cynical marketeers and allow them to be the first generation in a century not addicted to nicotine.

\section{Unknown long term effects}

Why would doctors want any part in giving approval to e-cigarettes? No other "treatment" would be accepted with the current level of evidence, and most doctors would be in breach of at least their own conscience by prescribing anything with likely but unknown long term adverse effects. To disguise e-cigarettes as a sensible harm reduction strategy will risk weakening sustainable smoking cessation strategies. $^{22}$

Instead, doctors should help to revive a decent NHS funded smoking cessation service, lobby politicians to increase taxes on products containing nicotine, and restrict smoking-as well as vaping-even more. Britain has a long tradition of leading the way in smoking prevention. Increasing these efforts while distancing itself from an industry that promotes addiction would again make the country a torchbearer in smoking prevention-instead of showing off a foolish example of British exceptionalism.

Competing interests: We have read and understood BMJ policy on declaration of interests and declare the following interests. NSH is chair of Action on Smoking and Health (UK). JG is chair of the European Respiratory Society's tobacco control committee. AB is the European Respiratory Society's guidelines director. The statements are personal and do not necessarily represent those of our employers.

Provenance and peer review: Commissioned; not externally peer reviewed.

Medicines and Healthcare Products Regulatory Agency. Guidance for licensing electronic cigarettes and other inhaled nicotine-containing products as medicines. Updated 29 Oct 2021. https://www.gov.uk/guidance/licensing-procedure-for-electronic-cigarettes-as-medicines

2 Britton J, Arnott D, McNeill A, Hopkinson NTobacco Advisory Group of the Royal College of Physicians. Nicotine without smoke-putting electronic cigarettes in context. BM/2016:353:11745. doi: 10.1136/bmj.i1745 pmid: 27122374

Shahab L, Goniewicz ML, Blount BC, etal. Nicotine, carcinogen, and toxin exposure in long-term e-cigarette and nicotine replacement therapy users: a cross-sectional study. Ann Intern Med 2017:166:390-400. doi: 10.7326/M16-1107 pmid: 28166548

4 Committee on Toxicity of Chemicals in Food Consumer Products and the Environment. Statement on the potential toxicological risks from electronic nicotine (and non-nicotine) delivery systems (E(N)NDS-e-cigarettes). 2020. https://cot.food.gov.uk/sites/default/files/202009/COT\%20E\%28N\%29NDS\%20statement\%202020-04.pdf

Action on Smoking and Health. Use of e-cigarettes (vapes) among adults in Great Britain. 2021 https://ash.org.uk/information-and-resources/fact-sheets/statistical/use-of-e-cigarettes-among adults-in-great-britain-2021/

6 Action on Smoking and Health. Use of electronic cigarettes among young people in Great Britain. Jun 2021. https://ash.org.uk/wp-content/uploads/2021/07/Use-of-e-cigarettes-among-youngpeople-in-Great-Britain-2021.pdf

7 Hartmann-Boyce J, McRobbie H, Lindson N, etal. Electronic cigarettes for smoking cessation. Cochrane Database Syst Rev 2021;4:CD010216 doi: 10.1002/14651858.CD010216.pub5. pmid: 33913154

8 National Institute for Health and Care Excellence. Tobacco: preventing uptake, promoting quitting and treating dependence (NICE guideline [NG209]): 1.12-Stop-smoking interventions. 30 Nov 2021. https://www.nice.org.uk/guidance/ng209/chapter/Recommendations-on-treating-tobaccodependence\#stop-smoking-interventions

9 All Party Parliamentary Group on Smoking and Health. Delivering a smokefree 2030: the All Party Parliamentary Group on Smoking and Health recommendations for the Tobacco Control Plan 2021. 9 Jun 2021. https://ash.org.uk/about-ash/all-party-parliamentary-group-on-smokinghealth/inquiries-reports/deliveringasf2030appgtcp2021/

10 Zafeiridou M, Hopkinson NS, Voulvoulis N. Cigarette smoking: an assessment of tobacco's global environmental footprint across its entire supply chain. Environ Sci Technol 2018;52:8087-94. doi: 10.1021/acs.est.8b01533 pmid: 29968460

11 Murray CJL, Aravkin AY, Zheng P, etalGBD 2019 Risk Factors Collaborators. Global burden of 87 risk factors in 204 countries and territories, 1990-2019: a systematic analysis for the Global Burden of Disease Study 2019. Lancet 2020;396:1223-49. doi: 10.1016/S0140-6736(20)30752-2 pmid: 33069327

12 Smoking in England. Discover major findings relating to smoking in England. Updated Jan 2021 https://smokinginengland.info/graphs/annual-findings

13 World Health Organization. Tobacco. 26 Jul 2021. https://www.who.int/news-room/factsheets/detail/tobacco

14 Hedman L, Galanti MR, Ryk L, Gilljam H, Adermark L. Electronic cigarette use and smoking cessation in cohort studies and randomized trials: A systematic review and meta-analysis. Tob Prev Cessat 2021;7:62. doi: 10.18332/tpc/142320. pmid: 34712864

15 Hajek P, Phillips-Waller A, Przulj D, etal. A randomized trial of e-cigarettes versus nicotine-replacement therapy. N Engl J Med 2019;380:629-37. doi: 10.1056/NEJMoa1808779 pmid: 30699054

16 Barufaldi LA, Guerra RL, de Albuquerque RCR, etal. Risk of smoking relapse with the use of electronic cigarettes: A systematic review with meta-analysis of longitudinal studies. Tob Prev Cessat 2021;29:29. doi: 10.18332/tpc/132964. pmid: 33928198

17 Tobacco Tactics. E-cigarettes. Updated 15 Mar 2021. https://tobaccotactics.org/wiki/e-cigarettes

18 Gornall J. Public Health England's troubled trail. BMJ2015;351:h5826. doi: 10.1136/bmj.h5826. pmid: 26534902

19 Miyashita L, Foley G. E-cigarettes and respiratory health: the latest evidence. J Physiol 2020;598:5027-38. doi: 10.1113/JP279526 pmid: 32495367 
20 Kaufman J. Everything old is new again: how the vaping industry borrowed banned practices of the tobacco industry (thesis). University of lowa. 2021. https://iro.uiowa.edu/discovery/fulldisplay/alma9984110018402771/0110WA_INST:ResearchRepository

21 Aladeokin A, Haighton C. Is adolescent e-cigarette use associated with smoking in the United Kingdom?: A systematic review with meta-analysis. Tob Prev Cessat 2019;5:15.

doi: 10.18332/tpc/108553. pmid: 32411879

22 Pisinger C, Dagli E, Filippidis FT, etalERS Tobacco Control Committee, on behalf of the ERS. ERS and tobacco harm reduction. Eur Respir /2019;54:1902009.

doi: 10.1183/13993003.02009-2019 pmid: 31801824 